\title{
A Simple Implement for Assessing the Survival of Elderly Patients With Melanoma Irradiated for Cerebral Metastases
}

\author{
TRANG NGUYEN $^{1}$, STEFAN JANSSEN ${ }^{1,2}$, STEVEN E. SCHILD $^{3}$ and DIRK RADES ${ }^{1}$ \\ ${ }^{1}$ Department of Radiation Oncology, University of Lübeck, Lübeck, Germany; \\ ${ }^{2}$ Medical Practice for Radiotherapy and Radiation Oncology, Hannover, Germany; \\ ${ }^{3}$ Department of Radiation Oncology, Mayo Clinic, Scottsdale, AZ, U.S.A.
}

\begin{abstract}
Background/Aim: Secondary brain lesions occur commonly in patients with advanced melanoma. Despite increasing use of local therapies, many elderly patients qualify for whole-brain radiotherapy (WBRT). For these patients, a survival score was created. Patients and Methods: Seven characteristics were retrospectively investigated in 35 elderly ( $\geq 65$ years) patients with melanoma, namely WBRT regimen, age, gender, Karnofsky performance score (KPS), number of brain lesions, non-cerebral metastases and interval from melanoma diagnosis to WBRT. Results: Age $\leq 71$ years $(p=0.044)$ and KPS $\geq 80 \%(p=0.005)$ were significantly associated with more favorable survival. Based on these characteristics, patients received $0(n=13), 1$ $(n=12)$ or 2 points $(n=10)$. Two prognostic groups were designed, 0 or 1 point vs. 2 points, with actuarial 6-month survival rates of $12 \%$ and $48 \%$, respectively $(p=0.002)$. Conclusion: This simple implement allows quick estimation of the survival of elderly patients receiving WBRT for cerebral metastases from melanoma.
\end{abstract}

Melanomas account for 5-10\% of malignant tumors spreading to the brain (1). For many patients with few secondary brain lesions, local therapies, namely surgery and different types of stereotactic radiotherapy, are used, either alone or combined with systemic therapies (2-6). In patients with more than a few lesions, whole-brain radiotherapy (WBRT) is quite often delivered. Many patients with melanoma developing cerebral metastases belong to the age group of 65 years and older.

This article is freely accessible online.

Correspondence to: Professor Dirk Rades, MD, Department of Radiation Oncology, University of Lübeck, Lübeck, Ratzeburger Allee 160, 23562 Lübeck, Germany. Tel: +49 45150045401; Fax: +49 45150045404; e-mail: rades.dirk@gmx.net

Key Words: Melanoma, cerebral metastases, elderly patients, wholebrain radiotherapy, survival, prognostic tool.
This group requires particular attention, since these patients more often have other diseases and reduced function of organs such as liver, kidney and bone marrow compared to younger patients. Elderly patients may be unable to withstand intensive local and systemic therapies and, therefore, receive WBRT alone. For the treatment of cerebral metastases, different WBRT regimens are available including 5×4 Gy (overall treatment time of 1 week), $10 \times 3$ Gy ( 2 weeks) and regimens with doses beyond $30 \mathrm{~Gy}$ (35-40 Gy with fractions of 2.0-3.0 Gy each, lasting 2.5 to 4 weeks). When selecting a WBRT regimen for an elderly patient with melanoma, physicians should consider the remaining lifespan. For patients with a reduced lifespan, short-term WBRT (i.e. $5 \times 4$ Gy) appears to be appropriate, since this regimen was shown to have similar outcomes compared to longer programs in patients with poor survival prognoses (7). On the contrary, for patients expected to have longer remaining lifetime, longerterm WBRT regimens may be beneficial in terms of increased cerebral control and survival (8). Therefore, physicians would like to be able to estimate a patient's prognosis before the start of WBRT. This study was performed to support physicians during the decision-making process. It aimed to create a simple tool that allows estimating the survival prognosis following WBRT of elderly patients with melanoma presenting with cerebral metastases.

\section{Patients and Methods}

Thirty-five melanoma patients aged $\geq 65$ years, who received WBRT for cerebral metastases, were analyzed in a retrospective way within this study, which received approval from the Ethics Committee (AZ19-011A). The data of several patients had been obtained from an existing database and had been used for other retrospective studies (9-13). In the current study, WBRT regimen $(5 \times 4$ Gy vs. $10 \times 3$ Gy vs. $12-20 \times 2-3$ Gy) and six pre-WBRT characteristics were analyzed for associations with survival. Distributions of the seven characteristics are shown in Table I. Pre-WBRT characteristics were age ( $\leq 71 v s . \geq 72$ years, median $=72$ years), gender (female $v s$. male), Karnofsky performance score ( $\leq 70 \%$ vs. $\geq 80 \%$, median $=70 \%)$, number of cerebral tumors [1-3 (limited) $v s . \geq 4$ (multiple)], non- 
Table I. Distribution of the evaluated characteristics.

\begin{tabular}{llc}
\hline Characteristic & & $\begin{array}{c}\text { Number of } \\
\text { patients }(\%)\end{array}$ \\
\hline WBRT regimen & $5 \times 4$ Gy & $8(22.9)$ \\
& $10 \times 3$ Gy & $18(51.4)$ \\
& $12-20 \times 2-3$ Gy & $9(25.7)$ \\
Age & $\leq 71$ Years & $17(48.6)$ \\
& $\geq 72$ Years & $18(51.4)$ \\
Gender & Female & $8(22.9)$ \\
Karnofsky performance score & Male & $27(77.1)$ \\
& $\leq 70 \%$ & $20(57.1)$ \\
Number of brain metastases & $\geq 80 \%$ & $15(42.9)$ \\
\multirow{2}{*}{ Extracranial metastases } & $1-3$ (Limited) & $12(34.3)$ \\
Interval from melanoma & No (Multiple) & $23(65.7)$ \\
diagnosis until WBRT & Yes & $5(14.3)$ \\
& $\leq 34$ Months & $30(85.7)$ \\
& $\geq 35$ Months & $18(51.4)$ \\
\end{tabular}

WBRT: Whole-brain radiotherapy.

cerebral metastases (no $v s$. yes), and period from melanoma diagnosis until WBRT ( $\leq 34 v s . \geq 35$ months, median=34 months).

The survival analyses were performed with Kaplan-Meier method plus log-rank test. Characteristics that were significantly $(p<0.05)$ associated with survival after WBRT were used to create the prognostic tool. For each significant characteristic, points were assigned, namely 0 points in the case of less favorable survival and 1 point in the case of more favorable survival. The total points for patients were calculated by adding their individual points related to significant characteristics.

\section{Results}

Age $\leq 71$ years $(p=0.044)$ and KPS of $\geq 80 \%(p=0.005)$ were significantly associated with more favorable outcomes (Table II). Therefore, these characteristics were used to create the prognostic tool. The following points were assigned: 0 points for age $\geq 72$ years and KPS of $\leq 70 \%$, respectively, and 1 point for age $\leq 71$ years and KPS of $\geq 80 \%$. Thus, the patients received total scores of $0(n=13), 1(n=12)$ or 2 points $(n=10)$. Survival rates were $8 \%, 25 \%$ and $60 \%$ at 3 months, and $8 \%$, $17 \%$ and $48 \%$ at 6 months $(p=0.007)$. Two prognostic groups were designed, with 0 or 1 point, and 2 points. Corresponding 3 -month survival rates were $16 \%$ and $60 \%$; 6-month survival rates were $12 \%$ and $48 \%$, respectively ( $p=0.002$, Figure 1$)$.

\section{Discussion}

Considerable research is carried out to improve the survival prognoses of patients with metastatic melanoma (2-6, 9-13). The prognoses of many elderly patients developing cerebral metastases from melanoma are very limited. Besides newer systemic treatment approaches, personalization of the
Table II. Six-month survival rates after whole-brain irradiation (univariate analyses).

\begin{tabular}{|c|c|c|c|}
\hline & $\begin{array}{l}\text { At } 3 \text { months } \\
(\%)\end{array}$ & $\begin{array}{c}\text { At } 6 \text { months } \\
(\%)\end{array}$ & $p$-Value \\
\hline \multicolumn{4}{|l|}{ WBRT regimen } \\
\hline $5 \times 4$ Gy & 13 & 13 & \multirow[t]{3}{*}{0.14} \\
\hline $10 \times 3 \mathrm{~Gy}$ & 44 & 32 & \\
\hline $12-20 \times 2-3 \mathrm{~Gy}$ & 11 & 11 & \\
\hline \multicolumn{4}{|l|}{ Age } \\
\hline$\leq 71$ Years & 41 & 34 & \multirow[t]{2}{*}{0.044} \\
\hline$\geq 72$ Years & 17 & 11 & \\
\hline \multicolumn{4}{|l|}{ Gender } \\
\hline Female & 25 & 25 & \multirow[t]{2}{*}{0.46} \\
\hline Male & 29 & 22 & \\
\hline \multicolumn{4}{|c|}{ Karnofsky performance score } \\
\hline$\leq 70 \%$ & 10 & 10 & \multirow[t]{2}{*}{0.005} \\
\hline$\geq 80 \%$ & 53 & 38 & \\
\hline \multicolumn{4}{|c|}{ Number of brain metastases } \\
\hline $1-3$ (Limited) & 42 & 25 & \multirow[t]{2}{*}{0.76} \\
\hline$\geq 4$ (Multiple) & 22 & 22 & \\
\hline \multicolumn{4}{|c|}{ Extracranial metastases } \\
\hline No & 40 & 40 & \multirow[t]{2}{*}{0.14} \\
\hline Yes & 27 & 19 & \\
\hline \multicolumn{4}{|c|}{$\begin{array}{l}\text { Interval from melanoma } \\
\text { diagnosis until WBRT }\end{array}$} \\
\hline$\leq 34$ Months & 22 & 17 & \multirow[t]{2}{*}{0.16} \\
\hline$\geq 35$ Months & 35 & 28 & \\
\hline
\end{tabular}

WBRT: Whole-brain radiotherapy. Significant $p$-values are shown in bold.

treatment can lead to improved outcomes. To facilitate the selection of an optimally personalized treatment, survival scores are important. This also applies to the choice of the most appropriate WBRT regimen. Survival scores are already available for different types of radiotherapy and primary tumor types $(4,9,10,14)$. In our study, a specific implement for estimating the survival prognoses of elderly patients receiving WBRT for cerebral metastases from melanoma has been added. Patients belonging to the 0-to-1-point group achieved a median survival of only 1 month, and 3- and 6-month survival rates were only $16 \%$ and $12 \%$, respectively. Thus, these patients should receive short-term WBRT with $5 \times 4$ Gy (7). Moreover, since a randomized study performed in patients with cerebral metastases from lung cancer and quite limited prognoses demonstrated that best supportive care was not significantly inferior to the same regimen plus WBRT with $5 \times 4 \mathrm{~Gy}$, one may also consider omitting WBRT for the patients of the 0-to-1-point group in the present study (15).

On the contrary, patients of the 2-point group in the current study achieved a median survival of 6 months, with the 3- and 6-month survival of $60 \%$ and $48 \%$, respectively. Thus, these patients would appear to be more adequately treated with a longer-term WBRT program, since previous studies have suggested increased cerebral control and 


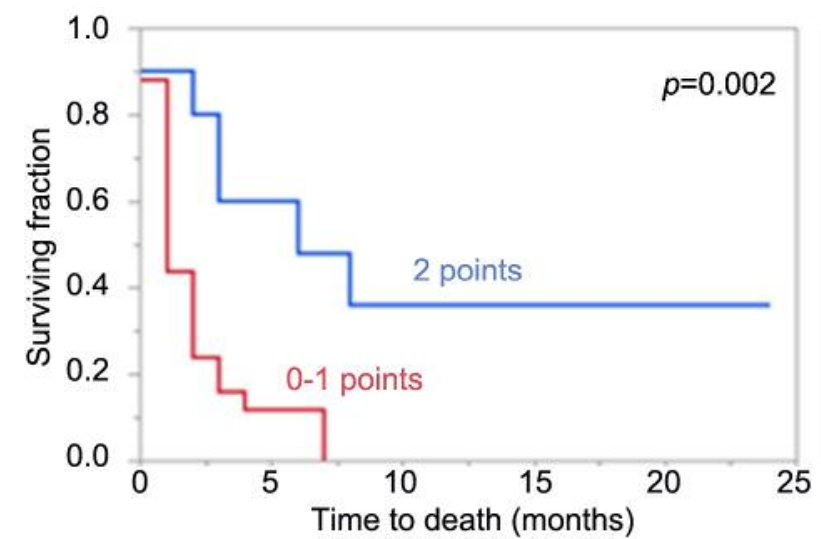

Figure 1. Kaplan-Meier curves of the groups with 0-1 points $(n=25)$ and 2 points $(n=10)$ with respect to survival after whole-brain radiotherapy.

survival using WBRT with higher doses (8). In general, the outcomes of patients developing cerebral metastases from melanoma may be improved by combining radiotherapy and immunotherapy (16). This applies particularly to those who have intermediate or favorable prognoses. However, one should be aware of the increased risk of side-effects including necrosis of normal brain tissue when immunotherapy is added. When using this new tool to estimate a patient's survival time and to select a WBRT regimen, the limitations of our study, namely its small sample size and its retrospective design, need to be regarded.

In summary, a simple tool was developed that allows judging the remaining lifespans of elderly patients treated with WBRT for cerebral metastases from melanoma. This tool can be useful when aiming to pick the most suitable individual WBRT regimen.

\section{Conflicts of Interest}

On behalf of all Authors, the corresponding Author states that there are no conflicts of interest related to this study.

\section{Authors' Contributions}

T.N., S.J., S.E.S. and D.R. participated in the study design. T.N., S.J. and D.R. provided the data that were analyzed and interpreted by S.E.S. and D.R. S.E.S. and D.R. wrote the article that was reviewed and approved by all Authors.

\section{References}

1 Siegel RL, Miller KD and Jemal A: Cancer statistics, 2019. CA Cancer J Clin 69: 7-34, 2019. PMID: 30620402. DOI: 10.3322/ caac. 21551

2 Stera S, Balermpas P, Blanck O, Wolff R, Wurster S, Baumann R, Szücs M, Loutfi-Krauss B, Wilhelm ML, Seifert V, Rades D, Rödel C, Dunst J, Hildebrandt G, Arnold A, Meissner M and
Kähler KC: Stereotactic radiosurgery combined with immune checkpoint inhibitors or kinase inhibitors for patients with multiple brain metastases of malignant melanoma. Melanoma Res 29: 187-195, 2019. PMID: 30802230. DOI: 10.1097/CMR. 0000000000000542

3 Huttenlocher S, Dziggel L, Hornung D, Blanck O, Schild SE and Rades D: A new prognostic instrument to predict the probability of developing new cerebral metastases after radiosurgery alone. Radiat Oncol 9: 215, 2014. PMID: 25240823. DOI: 10.1186/ 1748-717X-9-215

4 Sehmisch L, Huttenlocher S, Schild SE and Rades D: Estimating survival of patients receiving radiosurgery alone for cerebral metastasis from melanoma. J Dermatol 41: 918-921, 2014. PMID: 25154301. DOI: 10.1111/1346-8138.12599

5 Azijli K, Stelloo E, Peters GJ and van den Eertwegh AJ: New developments in the treatment of metastatic melanoma: immune checkpoint inhibitors and targeted therapies. Anticancer Res 34: 1493-1505, 2014. PMID: 24692676.

6 Walter L and Heinzerling L: BRAF inhibitors and radiation do not act synergistically to inhibit WT and V600E $B R A F$ human melanoma. Anticancer Res 38: 1335-1341, 2018. PMID: 29491057. DOI: 10.21873 /anticanres. 12356

7 Rades D, Kieckebusch S, Lohynska R, Veninga T, Stalpers LJ, Dunst $\mathrm{J}$ and Schild SE: Reduction of overall treatment time in patients irradiated for more than three brain metastases. Int $\mathbf{J}$ Radiat Oncol Biol Phys 69: 1509-1513, 2007. PMID: 17689033. DOI: 10.1016/j.ijrobp.2007.05.014

8 Rades D, Panzner A, Dziggel L, Haatanen T, Lohynska R and Schild SE: Dose-escalation of whole-brain radiotherapy for brain metastasis in patients with a favorable survival prognosis. Cancer 118: 3852-3859, 2012. PMID: 22170514. DOI: $10.1002 /$ cncr.26680

9 Rades D, Sehmisch L, Hansen HC, Dziggel L, Janssen S and Schild SE: Comparison of diagnosis-specific survival scores for patients with cerebral metastases from malignant melanoma including the new WBRT-30-MM. Anticancer Res 39: 15011505, 2019. PMID: 30842188. DOI: 10.21873/anticanres.13268

10 Sehmisch L, Schild SE and Rades D: Development of a survival score for patients with cerebral metastases from melanoma. Anticancer Res 37: 249-252, 2017. PMID: 28011499. DOI: 10.21873/anticanres.11314

11 Rades D, Sehmisch L, Janssen S and Schild SE: Prognostic factors after whole-brain radiotherapy alone for brain metastases from malignant melanoma. Anticancer Res 36: 6637-6640, 2016. PMID: 27919995. DOI: 10.21873/anticanres.11271

12 Meyners T, Heisterkamp C, Kueter JD, Veninga T, Stalpers LJ, Schild SE and Rades D: Prognostic factors for outcomes after whole-brain irradiation of brain metastases from relatively radioresistant tumors: A retrospective analysis. BMC Cancer 10: 582, 2010. PMID: 20977700. DOI: 10.1186/1471-2407$10-582$

13 Rades D, Sehmisch L, Bajrovic A, Janssen S and Schild SE: Comparison of $20 \times 2$ Gy and $12 \times 3$ Gy for whole-brain irradiation of multiple brain metastases from malignant melanoma. In Vivo 30: 917-919, 2016. PMID: 27815480. DOI: 10.21873/invivo.11013

14 Rades D, Dziggel and Schild SE: A specific survival score for patients receiving local therapy for single brain metastasis from a gynecological malignancy. In Vivo 32: 825-828, 2018. PMID: 29936465. DOI: 10.21873/invivo.11314 
15 Mulvenna P, Nankivell M, Barton R, Faivre-Finn C, Wilson P, McColl E, Moore B, Brisbane I, Ardron D, Holt T, Morgan S, Lee C, Waite K, Bayman N, Pugh C, Sydes B, Stephens R, Parmar MK and Langley RE: Dexamethasone and supportive care with or without whole brain radiotherapy in treating patients with non-small cell lung cancer with brain metastases unsuitable for resection or stereotactic radiotherapy (QUARTZ): results from a phase 3, non-inferiority, randomised trial. Lancet 388(10055): 2004-2014, 2016. PMID: 27604504. DOI: $10.1016 / \mathrm{S} 0140-6736(16) 30825-\mathrm{X}$
16 Petrelli F, De Stefani A, Trevisan F, Parati C, Inno A, Merelli B, Ghidini M, Bruschieri L, Vitali E, Cabiddu M, Borgonovo K, Ghilardi M, Barni S and Ghidini A: Combination of radiotherapy and immunotherapy for brain metastases: A systematic review and meta-analysis. Crit Rev Oncol Hematol 144: 102830, 2019. PMID: 31733443. DOI: 10.1016/j.critrevonc.2019.102830

Received February 24, 2020

Revised March 5, 2020

Accepted March 6, 2020 